\title{
A novel organotriphosphoryl polyoxomolybdate: synthesis, crystal structure, and experimental and theoretical investigation of the absorption spectra
}

5 Shi-Zheng Wen ${ }^{a}$, Wei-Qiu Kan ${ }^{\mathrm{b}, *}$, Dong-Lei $\mathrm{Xu}^{\mathrm{a}}$

${ }^{a}$ Jiangsu Province Key Laboratory of Modern Measurement Technology and Intellige, School of Physics and Electronic Electrical Engineering, Huaiyin Normal University, Huaian 223300, People's Republic of China

${ }^{b}$ Jiangsu Province Key Laboratory for Chemistry of Low-Dimensional Materials, School of Chemistry and Chemical Engineering, Huaiyin Normal University, Huaian 223300, People’s Republic of China

* Correspondence author

15

E-mail: kanwq@hytc.edu.cn (W. Kan)

Tel : +8651783525663

Fax: +86 51783525663

20 ABSTRACT

A novel organotriphosphoryl polyoxomolybdate, namely, $\left[\left(\mathrm{CH}_{3}\right)_{4} \mathrm{~N}\right]\left[\left(\mathrm{CH}_{3}\right)_{3} \mathrm{~N}\right]\left[\mathrm{R}\left(\mathrm{PO}_{3} \mathrm{H}\right)_{2}\left(\mathrm{PO}_{3}\right)\right] \mathrm{PMo}_{9} \mathrm{O}_{28}$ (1), where $\mathrm{R}=\mathrm{C}_{12} \mathrm{H}_{15}$, has been synthesized hydrothermally. The structure of $\mathbf{1}$ contains one trivacant $\left[\mathrm{PMo}_{9} \mathrm{O}_{34}\right]$ subunit on which is grafted one $\mathrm{R}(\mathrm{POH})_{2}(\mathrm{PO})$ through three P-O-Mo bridges. 25 Compound $\mathbf{1}$ is the first example of polyoxomolybdate decorated by three phosphonate groups from one organotriphosphonic acid. The structure of the compound was determined by single-crystal X-ray diffraction analysis and further characterized by infrared spectrum (IR) and elemental analysis. Moreover, the UV-vis absorption spectrum of the compound has been investigated experimentally and 
theoretically.

Keywords: Polyoxomolybdate; organophosphoryl; theoretically; experimentally; absorption spectrum

During the past few years, polyoxometalates (POMs) have attracted much interest due to their potential applications in the fields of magnetism [1-3], catalysis [4-6], sensing [7-9], and so on. It has long been recognized that the solubility and other physical properties of the POMs can be finely modified by introducing appropriate organic or organometallic groups onto the surface of POMs [10]. Therefore, the organic and organometallic derivatives of POMs have more selective applications [11-13]. So far, several kinds of organic derivatives of POMs have been explored, including organophosphoryl, organoarsonyl, organosilyl, organogermyl, organotin POMs derivatives, and so on [13].

In this regard, our attention mainly focused on the trivacant organophosphoryl POMs derivatives. Up to now, most of the reported trivacant organophosphoryl POMs were obtained by the directly reaction of organotriphosphonic acid ligands with trivacant POMs [10-13]. In this work, we report a new method to synthesize the trivacant organophosphoryl POMs. We use organotriphosphonic acid ligand and saturated Keggin type polyoxomolybdate as reactants to synthesize trivacant organophosphoryl polyoxomolybdate under the hydrothermal condition.

The target compound was synthesized by the reaction of the organotriphosphonic acid 2,4,6-trimethylbenzene-1,3,5-tris(methylenephosphonic acid) $[14,15]\left(\mathrm{H}_{6} \mathrm{~L}\right.$, chart 1), $\mathrm{H}_{3} \mathrm{PMo}_{12} \mathrm{O}_{40} \cdot \mathrm{H}_{2} \mathrm{O}, \mathrm{CuCl}_{2} \cdot 2 \mathrm{H}_{2} \mathrm{O}$ and tetramethylammonium hydroxide (TMAH) in water [16]. From the formula we can see that the $\mathrm{Cu}$ (II) ions are not exist in the resultant compound. But if we remove $\mathrm{CuCl}_{2} \cdot 2 \mathrm{H}_{2} \mathrm{O}$ from the reaction mixture, no crystal can be obtained after the hydrothermal reaction.

Chart 1. View of the $\mathrm{H}_{6} \mathrm{~L}$ ligand used in this work. 
The structure of compound $\mathbf{1}$ was determined by single-crystal X-ray diffraction analysis and further characterized by infrared spectrum (IR) and elemental analysis. In addition, the UV-vis spectrum of the compound has been investigated experimentally and theoretically. We hope that our work will helpful for the further investigation of its potential applications.

Single-crystal X-ray diffraction analysis reveals that compound $\mathbf{1}$ crystallizes in the orthorhombic space group Pbcm [17]. The asymmetric unit of $\mathbf{1}$ consists of half a $\mathrm{R}(\mathrm{POH})_{2}(\mathrm{PO})$, half a $\left[\mathrm{PMo}_{9} \mathrm{O}_{34}\right]$ subunit, half a trimethylamine molecule and half a tetramethyl ammonium (TMA) cation. The trimethylamine molecule presumably was generated by the decomposition of the TMAH [18]. The P-O bond lengths are in the range of 1.498(5)-1.583(4) $\AA$, and the Mo-O bond distances are in the range of 1.658(5)-2.456(4) $\AA$ (Table S1). All these bond lengths are in the normal ranges as observed in other polyoxomolybdates [19-22]. The discrete structure of 1 contains one trivacant $\left[\mathrm{PMo}_{9} \mathrm{O}_{34}\right]$ subunit on which is grafted one $\mathrm{R}(\mathrm{POH})_{2}(\mathrm{PO})$ through three P-O-Mo bridges (Fig. 1). The $\left[\mathrm{PMo}_{9} \mathrm{O}_{34}\right]$ subunit has a $\beta$-A-Keggin structure, which is formed by removing a $\mathrm{M}_{3}$ cluster consists of corner shared octahedra from a saturated $\beta$-Keggin structure. Result from document indicates that a saturated Keggin type polyanion $\left[\mathrm{PM}_{12} \mathrm{O}_{40}\right]^{3-}$ can loose a $\left\{\mathrm{MO}_{13}\right\}$ cluster to form a $\left[\mathrm{PM}_{9} \mathrm{O}_{34}\right]^{9-}$ unit under basic conditions [23]. To the best of our knowledge, compound $\mathbf{1}$ is the first example of polyoxomolybdate decorated by three phosphonate groups from one organotriphosphonic acid ligand. Moreover, there are intermolecular $\mathrm{C}-\mathrm{H} \cdots \mathrm{O}$ hydrogen bonding interactions, which further extend the discrete structure into a 3D supramolecular framework (Table S2, Fig. 2).

Fig. 1. View of the discrete structure of $\mathbf{1}$.

Fig. 2. View of the 3D supramolecular framework of $\mathbf{1}$. 
dimethyl formamide (DMF). As shown in Fig. 3, compound 1 shows a main absorption peak at $319 \mathrm{~nm}$. In order to better understand the mechanism of the UV-vis absorption spectrum, we use the density functional theory (DFT) to get into the experimental data [24]. Based on the data of crystal structure, we use the Gaussian 09

5 software to carry out the electronic structure analysis [25]. We chose the hybrid B3LYP functional with basis set of LAN2DZ for Mo and 6-31G(d) for other elements to optimize the structure. The B3LYP functional is one of the most widely used functional to investigate the geometry of molecule with the balance of the amount of calculation and efficiency [26]. The cartesian coordinates of the molecule are listed in Table S3. The geometry calculated by theory corresponds well with the experimental data.

Fig. 3. The experimental (black dot) and computational (solid red line) patterns of the UV-Vis absorption spectra for the compound.

Based on the optimized structure, we used the time-dependent density functional theory (TD-DFT) method to investigate the UV-Vis spectra of the molecule and compared the results with the experimental data [27]. The M06-2X hybrid functional was chosen since it is more suitable to describe the excited states for the transition elements [28]. As shown in Fig. 3, the predicted absorption peak is at $308 \mathrm{~nm}$, which corresponds well with the experimental data $(319 \mathrm{~nm})$ with a slightly blue-shift. In the experiment, the measurement of the UV-Vis absorption spectrum of the compound was carried out in the DMF solution. So, in the theoretical simulation, the Polarizable Continuum Model (PCM) method was chosen to include the solvent reaction field. The main electronic transitions are from the organic ligand (occupied orbital) to the POM. For example, the absorption peak at $308 \mathrm{~nm}$ is mainly attributed to the electronic transitions from HOMO-1 to LUMO+5 and from HOMO-10 to LUMO with the large oscillator strength, and the main transitions assignments with the contributions are summarized in Table S4. As shown in Table S4, the transitions consist of two main wave lengths near $308 \mathrm{~nm}$. The largest electron transitions 
contributions are from HOMO-1 to LUMO+5 (34.45\%) and from HOMO-10 to LUMO (32.48\%) as discussed above. Other transitions, for example, from HOMO-10 to LUMO, although the occupied electrons distributions (HOMO-10) are among the whole molecule, the organic fragment plays important part (see Fig.4). More molecular orbitals for the compound with the dominant electron transitions are shown in Fig. 4, from which it can be clearly seen that the absorption originates mainly from the electron transitions from the organic donor fragment to the POM part.

Fig. 4. Molecular orbital diagrams for the compound involved in the dominant electron transition.

In conclusion, a novel organotriphosphoryl polyoxomolybdate based on a trivacant $\left[\mathrm{PMo}_{9} \mathrm{O}_{34}\right]$ subunit has been synthesized under the hydrothermal condition. It should be pointed out that compound $\mathbf{1}$ is the first example of polyoxomolybdate decorated by three phosphonate groups from one organotriphosphonic acid. Moreover, the UV-vis absorption spectrum of the compound has been investigated experimentally and theoretically in detail, and the experimental spectrum of $\mathbf{1}$ corresponds well with the simulated result. The results indicate that the absorption spectrum of compound $\mathbf{1}$ can be approximately simulated by the theoretical calculation.

\section{Acknowledgements}

This work was supported by the National Science Foundation of China (21403081 and 21401063), the Jiangsu Province NSF (Grant Nos. BK20140453 and BK20140452). The authors thanks for the computational supported and discussion of Prof. Yongqing Qiu (NENU).

Appendix A. Supplementary material

CCDC 1482308 contains the supplementary crystallographic data for this paper. These data can be obtained free of charge from The Cambridge Crystallographic Data 
Centre viawww.ccdc.cam.ac. uk/data_request/cif. Supplementary data associated with this article can be found, in the online version, at doi:???

\section{References}

5 [1] W. Salomon, Y.H. Lan, E. Riviere, S. Yang, C. Roch-Marchal, A. Dolbecq, C. Simonnet-Jegat, N. Steunou, N. Leclerc-Laronze, L. Ruhlmann, Single-Molecule Magnet Behavior of Individual Polyoxometalate Molecules Incorporated within Biopolymer or Metal-Organic Framework Matrices, Chem. Eur. J. 22 (2016) 6564-6574.

[2] O. Oms, S. Yang, W. Salomon, J. Marrot, A. Dolbecq, E. Riviere, A. Bonnefont, L. Ruhlmann, P. Mialane, Heteroanionic Materials Based on Copper Clusters, Bisphosphonates, and Polyoxometalates: Magnetic Properties and Comparative Electrocatalytic NOx Reduction Studies, Inorg. Chem. 55 (2016) 1551-1561.

[3] Z. Luo, P. Kögerler, R. Cao, C.L. Hill, Synthesis, Structure, and Magnetism of a Polyoxometalate with Coordinatively Unsaturated d-Electron-Transition Metal Centers, Inorg. Chem. 48 (2009) 7812-7817.

[4] X.J. Yang, M. Sun, H.Y. Zang, Y.Y. Ma, X.J. Feng, H.Q. Tan, Y.H. Wang, Y.G. Li, Hybrid Coordination Networks Constructed from-Keggin-Type Polyoxometalates and Rigid Imidazole-Based Bridging Ligands as New Carriers for Noble-Metal Catalysts, Chem. Asian J. 11 (2016) 858-867.

[5] F. Bentaleb, O. Makrygenni, D. Brouri, C.C. Diogo, A. Mehdi, A. Proust, F. Launay, R. Villanneau, Efficiency of Polyoxometalate-Based Mesoporous Hybrids as Covalently Anchored Catalysts, Inorg. Chem. 54 (2015) 7607-7616.

[6] K. Liu, Z.X. Yao, Y.F. Song, Polyoxometalates Hosted in Layered Double Hydroxides: Highly Enhanced Catalytic Activity and Selectivity in Sulfoxidation of Sulfides, Ind. Eng. Chem. Res. 54 (2015) 9133-9141.

[7] H.M. Zhang, J. Yang, W.Q. Kan, Y.Y. Liu, J.F. Ma, Photocatalytic Properties and Luminescent Sensing for $\mathrm{Cr}^{3+}$ Cations of Polyoxovanadates-Based Inorganic-Organic Hybrid Compounds with Multiple Lewis Basic Sites, Cryst. 
Growth Des. 16 (2016) 265-276.

[8] X.T. Wang, J.Q. Wang, R. Tsunashima, K. Pan, B. Cao, Y.F. Song, Electrospun Self-Supporting Nanocomposite Films of $\mathrm{Na}_{9}\left[\mathrm{EuW}_{10} \mathrm{O}_{36}\right] \cdot 32 \mathrm{H}_{2} \mathrm{O} / \mathrm{PAN}$ as pH-Modulated Luminescent Switch, Ind. Eng. Chem. Res. 52 (2013) 2598-2603.

5 [9] Y.J. Gong, Q.Z. Hu, C. Wang, L. Zang, L. Yu, Stimuli-Responsive Polyoxometalate/Ionic Liquid Supramolecular Spheres: Fabrication, Characterization, and Biological Applications, Langmuir, 32 (2016) 421-427.

[10] Z.G. Sun, Q. Liu, J.F. Liu, Synthesis and spectroscopic characterization of organophosphoryl polyoxotungstates of formula $\alpha-\mathrm{A}-[\mathrm{RP}(\mathrm{O})]_{2} \mathrm{PW}_{9} \mathrm{O}_{34}{ }^{5-}$, Main Group Met. Chem. 23 (2000) 189-191.

[11] Z.G. Sun, Z.M. Zhu, W.S. You, X.F. Zheng, Y.P. Gu, Synthesis and spectroscopic characterization of organothiophosphoryl polyoxotungstates $\alpha$ - $[\mathrm{RP}(\mathrm{S})]_{2} \mathrm{PW}_{9} \mathrm{O}_{34}{ }^{5-}$ $\left(\mathrm{R}=\mathrm{C}_{6} \mathrm{H}_{5}, \mathrm{C}_{6} \mathrm{H}_{11}\right)$, Chin. J. Chem. 23 (2005) 530-532.

[12] Z.G. Sun, J.X. Li, Q. Liu, J.F. Liu, Synthesis, structure and spectroscopic properties of organophosphoryl polyoxotungstates of formula $\alpha-\left[\mathrm{R}_{2} \mathrm{PW}_{9} \mathrm{O}_{34}\right]^{5-}(\mathrm{R}$ $\left.=\mathrm{C}_{6} \mathrm{H}_{5} \mathrm{P}(\mathrm{S}), \mathrm{C}_{6} \mathrm{H}_{11} \mathrm{P}(\mathrm{O})\right)$, Chin. Chem. Lett. 10 (1999) 971-972.

[13] P. Gouzerh, A. Proust, Main-Group Element, Organic, and Organometallic Derivatives of Polyoxometalates, Chem. Rev. 98 (1998) 77-112.

[14] G. Yucesan, M.H. Yu, C.J. O’Connor, J. Zubieta, Structural consequences of the steric effects of the organoimine ligand in the oxovanadium-organophosphonate/copper-mephenterpy family of hybrid oxides (mephenterpy $=$ 4'-(4-methyphenyl)-2,2':6',2"-terpyridine), CrystEngComm 7 (2005) 711-721.

[15] S. Zhou, Z.G. Kong, Q.W. Wang, C.B. Li, Synthesis, structure and photocatalytic property of a novel 3D $(3,8)$-connected metal-organic framework based on a flexible triphosphonate and a pentanuclear $\mathrm{Cu}(\mathrm{II})$ unit, Inorg. Chem. Commun. 25 (2012) 1-4.

[16] $\mathrm{H}_{6} \mathrm{~L}(0.04 \mathrm{~g}, 0.1 \mathrm{mmol}), \mathrm{CuCl}_{2} \cdot 2 \mathrm{H}_{2} \mathrm{O}(0.051 \mathrm{~g}, 0.3 \mathrm{mmol}), \mathrm{H}_{3} \mathrm{PMo}_{12} \mathrm{O}_{40} \cdot \mathrm{H}_{2} \mathrm{O}$ $(0.028 \mathrm{~g}, 0.015 \mathrm{mmol})$, TMAH $(0.015 \mathrm{~mL})$ and $8 \mathrm{~mL}$ water was sealed in a 15 $\mathrm{mL}$ Teflon reactor and heated at $180{ }^{\circ} \mathrm{C}$ for 3 days. After cooling to room 
temperature at a rate of $10{ }^{\circ} \mathrm{C} / \mathrm{h}$, green crystals of compound $\mathbf{1}$ were collected in a $32 \%$ yield. Anal. Calcd for $\mathrm{C}_{19} \mathrm{H}_{38} \mathrm{Mo}_{9} \mathrm{~N}_{2} \mathrm{O}_{37} \mathrm{P}_{4},\left(M_{\mathrm{r}}=1873.85\right)$ : C, 12.18; $\mathrm{H}$, 2.04; N, 1.50. Found: C, 12.09; H, 2.12; N, 1.61\%. IR data $\left(\mathrm{KBr}, \mathrm{cm}^{-1}\right): 3462$ (s), 1620 (s), 1551 (w), 1489 (s), 1444 (w), 1416 (w), 1379 (w), 1214 (w), 1076 (s), 951 (s), 809 (s), 579 (s), $544(\mathrm{~s})$.

[17] Crystallographic data of the compound was recorded on an Oxford Diffraction Gemini R CCD with graphite-monochromated Mo K $\alpha$ radiation $(\lambda=0.71073 \AA)$ at $293 \mathrm{~K}$. Absorption correction was applied using multi-scan technique. The hydrogen atoms of $\mathrm{H}_{2} \mathrm{~L}$ were generate geometrically and refined as riding atoms with $d(\mathrm{O}-\mathrm{H})=0.82 \AA$ and $U_{\text {iso }}=1.5 U_{\text {eq }}(\mathrm{O})$. Crystal data for $\mathbf{1}$ : $\mathrm{C}_{19} \mathrm{H}_{38} \mathrm{Mo}_{9} \mathrm{~N}_{2} \mathrm{O}_{37} \mathrm{P}_{4}, \mathrm{M}=1873.85$, orthorhombic, space group $P$ b c $m, T=293(2)$ $\mathrm{K}, a=18.9514(5), b=11.6892(3), c=21.7443(6) \AA, V=4816.9(2) \AA^{3}, \mathrm{Z}=4$, $D c=2.584 \mathrm{~g} / \mathrm{cm}^{3}$, a total of 17659 reflections were collected, of which 4293 were unique $\left(R_{\text {int }}=0.0454\right)$, final $R_{1}=0.0313$ for $\mathrm{I}>2 \sigma(I), w R_{2}=0.0698$ for all data, GOOF $=0.989$.

[18] X.Q. Wang, J. Huang, A.J. Jacobson, $\left[\left(\mathrm{CH}_{3}\right)_{4} \mathrm{~N}\right]\left[\left(\mathrm{C}_{5} \mathrm{H}_{5} \mathrm{NH}\right)_{0.8}\left(\left(\mathrm{CH}_{3}\right)_{3} \mathrm{NH}\right)_{0.2}\right]$ $-\mathrm{U}_{2} \mathrm{Si}_{9} \mathrm{O}_{23} \mathrm{~F}_{4}$ (USH-8): An Organically Templated Open-Framework Uranium Silicate, J. Am. Chem. Soc. 124 (2002), 15190-15191.

[19] Y. Guo, X.M. Li, T. Shi, C.H. Li, Y.G. Chen, H.Y. Wang, Double-linked chain in POM-based hybrids. Synthesis, crystal structure and properties of an inorganic-organic compound, Inorg. Chem. Commun. 65 (2016) 49-53.

[20] A.X. Tian, H.P. Ni, Y. Tian, X.B. Ji, G.C. Liu, J. Ying, Two Keggin compounds constructed from tri-/tetra-nuclear $\mathrm{Cu}$ clusters linked mono copper(II)-substituted phosphomolybdates, Inorg. Chem. Commun. 68 (2016) 50-55.

25 [21] X.J. Dui, X.Y. Wu, J.Z. Liao, T. Teng, W.M. Wu, W.B. Yang, Photocatalytic properties of two POM-templated organic-inorganic hybrid compounds, Inorg. Chem. Commun. 56 (2015) 112-115.

[22] S.Q. Wan, K. Yu, L. Wang, Z.H. Su, B.B. Zhou, Assembly of sandwich-type 3-D supramolecular coordination polymers based on hexa-molybdenum chain and $\left\{\mathrm{PMo}_{12} \mathrm{O}_{40}\right\}$ heteropolyanion, Inorg. Chem. Commun. 61 (2015) 113-117. 
[23] X.L. Wang, X.J. Liu, A.X. Tian, J. Ying, H.Y. Lin, G.C. Liu, Q. Gao, A novel $2 \mathrm{D} \rightarrow 3 \mathrm{D}\left\{\mathrm{Co}_{6} \mathrm{PW}_{9}\right\}$-based framework extended by semi-rigid bis(triazole) ligand, Dalton Trans. 41 (2012) 9587-9589.

[24] D. Ravelli, D. Dondi, M. Fagnoni, A. Albini, A. Bagno, Predicting the UV spectrum of polyoxometalates by TD-DFT, J. Comput. Chem, 32 (2011) 2983-2987.

[25] M.J. Frisch, G.W. Trucks, H.B. Schlegel, G.E. Scuseria, M.A. Robb, J.R. Cheeseman, G. Scalmani, V. Barone, B. Mennucci, G.A. Petersson, H. Nakatsuji, M. Caricato, X. Li, H.P. Hratchian, A.F. Izmaylov, J. Bloino, G. Zheng, J.L. Sonnenberg, M. Hada, M. Ehara, K. Toyota, R. Fukuda, J. Hasegawa, M. Ishida, T. Nakajima, Y. Honda, O. Kitao, H. Nakai, T. Vreven, J.A. Montgomery, Jr., J.E. Peralta, F. Ogliaro, M. Bearpark, J.J. Heyd, E. Brothers, K.N. Kudin, V.N. Staroverov, T. Keith, R. Kobayashi, J. Normand, K. Raghavachari, A. Rendell, J.C. Burant, S.S. Iyengar, J. Tomasi, M. Cossi, N. Rega, J.M. Millam, M. Klene, J.E. Knox, J.B. Cross, V. Bakken, C. Adamo, J. Jaramillo, R. Gomperts, R.E. Stratmann, O. Yazyev, A.J. Austin, R. Cammi, C. Pomelli, J.W. Ochterski, R.L. Martin, K. Morokuma, V.G. Zakrzewski, G.A. Voth, P. Salvador, J.J. Dannenberg, S. Dapprich, A.D. Daniels, O. Farkas, J.B. Foresman, J.V. Ortiz, J. Cioslowski, D.J. Fox, Gaussian09 W, Inc., Wallingford CT, 2013.

[26] A.D. Becke, A new mixing of Hartree-Fock and local density-functional theories, J. Chem. Phys. 98 (1993) 1372-1377.

[27] F. Trani, G. Scalmani, G.S. Zheng, I. Carnimeo, M.J. Frisch, V. Barone, Time-Dependent Density Functional Tight Binding: New Formulation and Benchmark of Excited States, J. Chem. Theory Comput. 7 (2011) 3304-3313.

[28] Y. Zhao, D.G. Truhlar, The M06 suite of density functionals for main group thermochemistry, thermochemical kinetics, noncovalent interactions, excited states, and transition elements: two new functionals and systematic testing of four M06-class functionals and 12 other functionals, Theor. Chem. Acc. 120 (2008) 215-241 
Figure captions

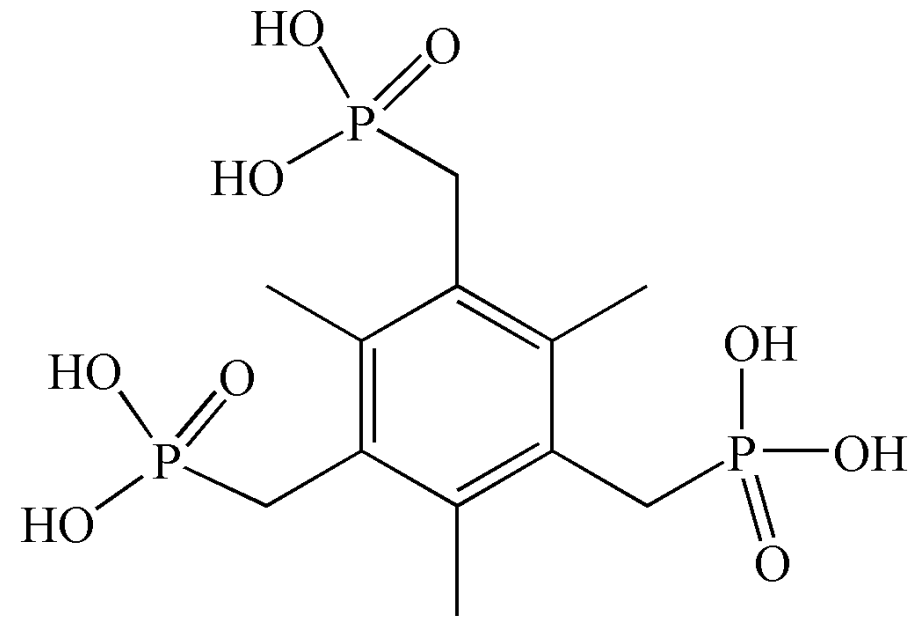

5 Chart 1. View of the $\mathrm{H}_{6} \mathrm{~L}$ ligand used in this work.

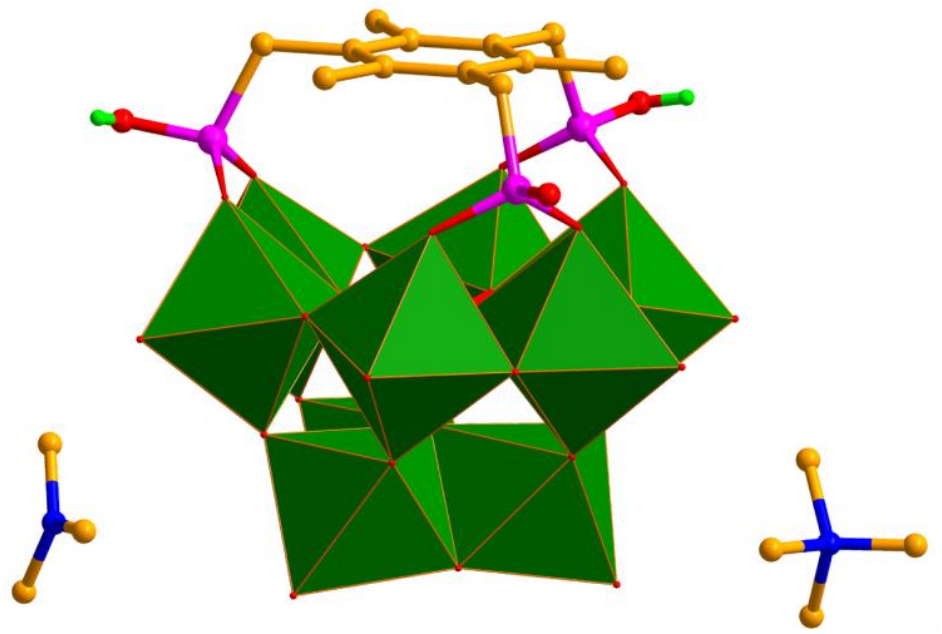

Fig. 1. View of the discrete structure of $\mathbf{1}$. 


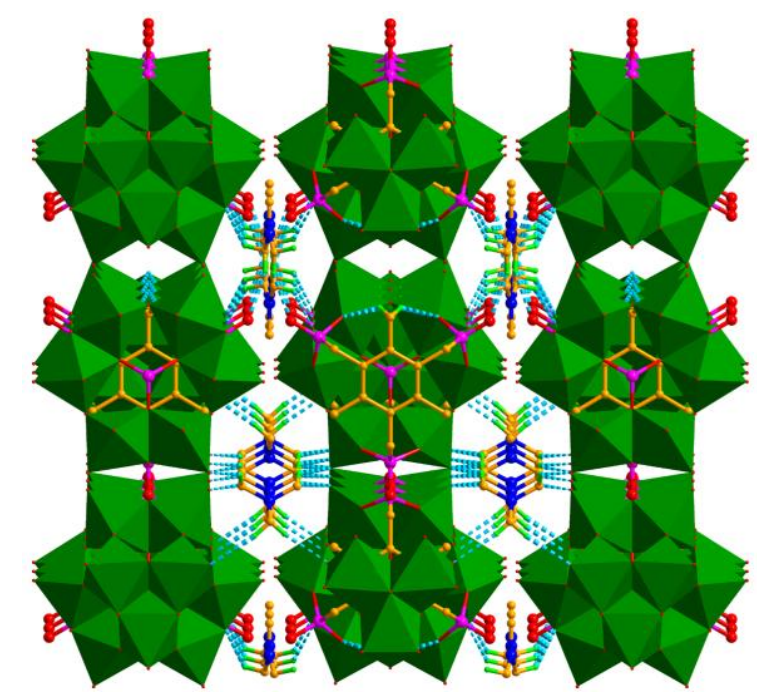

Fig. 2. View of the 3D supramolecular framework of $\mathbf{1}$.

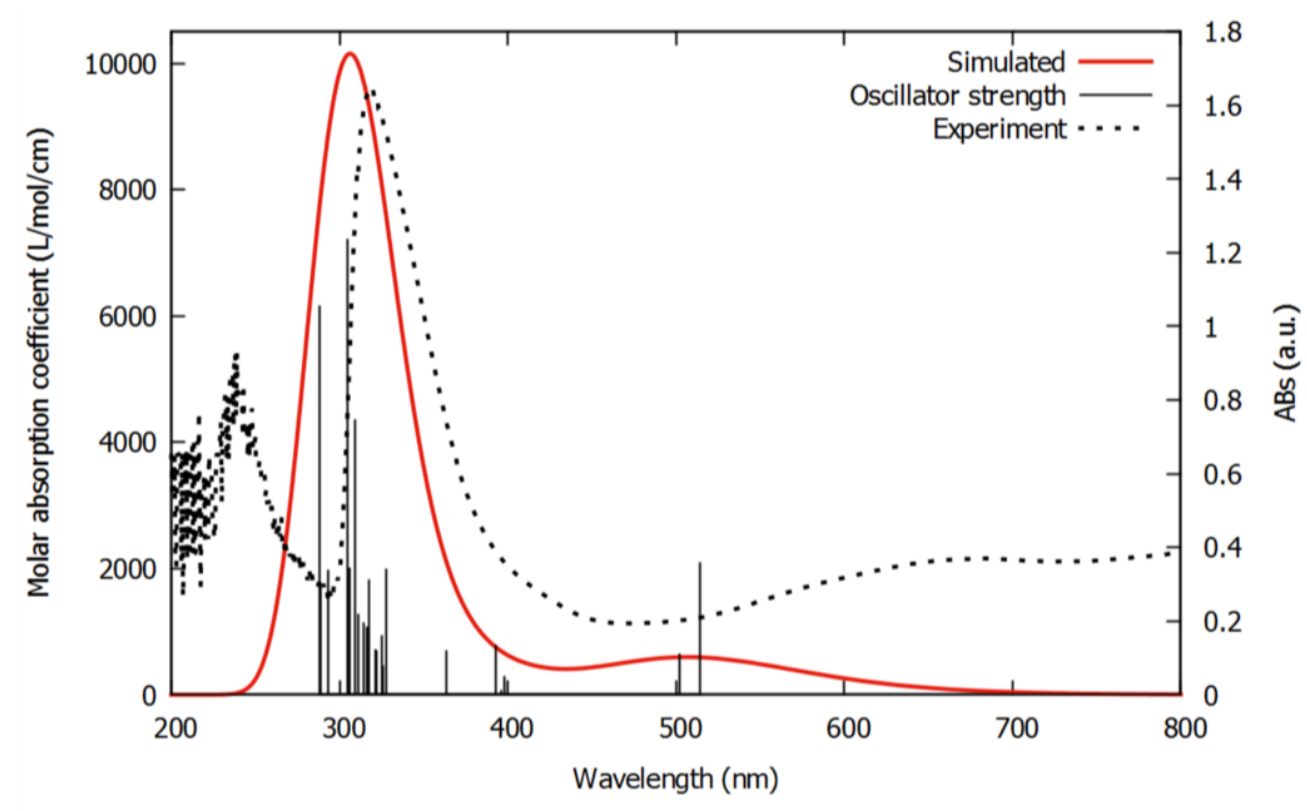

Fig. 3. The experimental (black dot) and computational (solid red line) patterns of the $\mathrm{UV}-\mathrm{Vis}$ absorption spectra for the compound. 

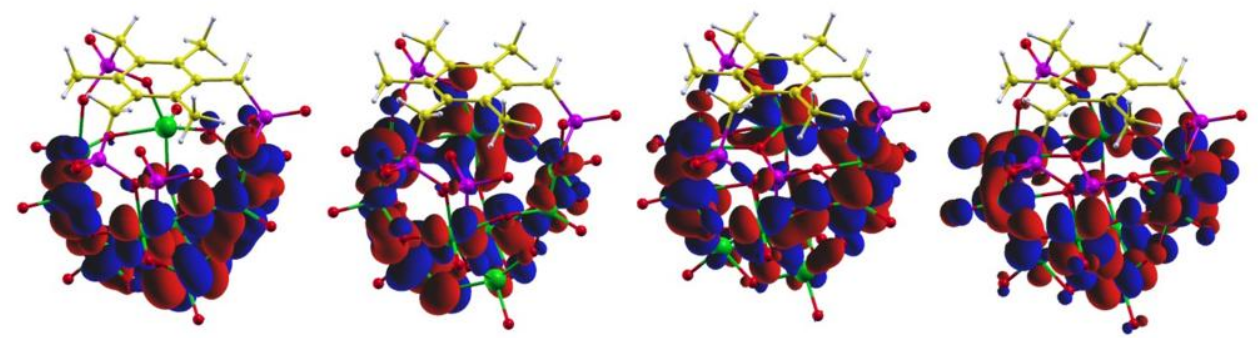

LUMO

$\mathrm{LUMO}+1$

$\mathrm{LUMO}+2$

$\mathrm{LUMO}+5$
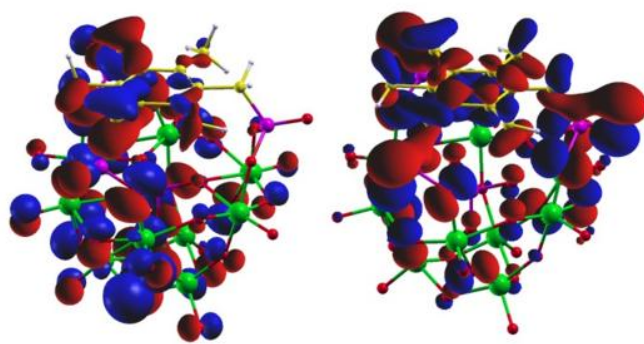

HOMO-15 HOMO-10
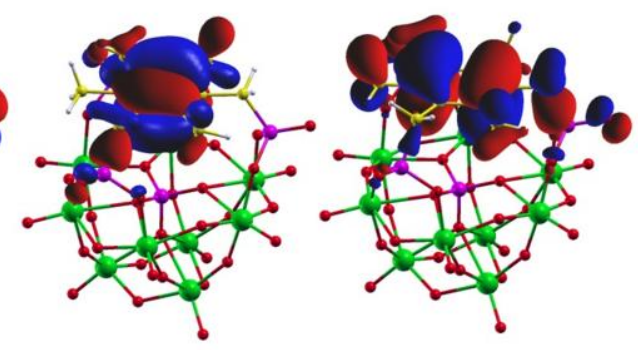

HOMO-1

HOMO

Fig. 4. Molecular orbital diagrams for the compound involved in the dominant electron transition. 


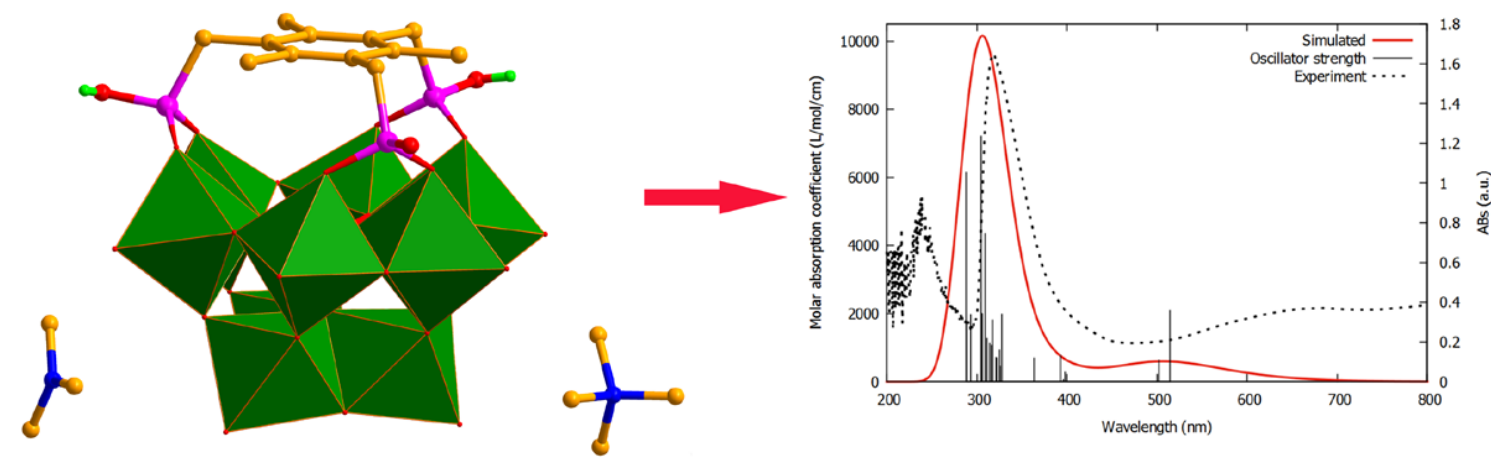


A novel organotriphosphoryl polyoxomolybdate has been prepared hydrothermally, where its absorption spectrum has been investigated experimentally and theoretically 